\title{
Intensive Agriculture Production in Low Consumption Energy Environment
}

\author{
J. Galvão ${ }^{1,2}$, A. Nabais ${ }^{3}$, H. Correia ${ }^{1}$, P. Amaro ${ }^{1}$, A. Negrão ${ }^{1,4}$, V. Ribeiro ${ }^{5,6}$ \\ ${ }^{1}$ Department of Electrical Engineering, ESTG - Leiria Polytechnic Institute, 2411-901 Leiria (Portugal) \\ Phone:+00351 244820300, e-mail: jrgalvao@ipleiria.pt; adelino.nabais@ecobie.pt \\ ${ }^{2}$ R\&D Unit, Institute for Systems Engineering and Computers /INESC Coimbra (Portugal) \\ ${ }^{3}$ ECOBIE - Engenharia Lda, Leiria (Portugal) \\ ${ }^{4}$ Instituto de Astrofísica e Ciências do Espaço, Lisboa (Portugal) \\ ${ }^{5}$ ciTechCare - School of Health Sciences, Leiria Polytechnic Institute, Leiria (Portugal) \\ ${ }^{6}$ GeoBioTec - Faculdade de Ciências e Tecnologia, Universidade Nova de Lisboa, 2829-516 Caparica (Portugal)
}

\begin{abstract}
This work involves the study and dissemination of energy management practices for greater energy efficiency in a context of renewable energies, intensive production of flowers in greenhouses and the integration of data sensors, which enables the system to connect and exchange information from these systems to end users in a communication network. These several variavles can be monitored in real time with the support of the Internet of Things (IoT). It is intended to conceive a software and hardware prototype, in one new environment consumption, with the change for renewable energy sources, for better control of the variables involved in plant growth and more sustainability, in this intensive agricultural production sector.
\end{abstract}

Key words: efficiency, renewable energy, data management, supervision, greenhouses

\section{Introduction}

The current trend of designing systems with features that perform a diversity of integrative links between IoT and cyber-physical worlds, is a path that in the short term will lead to levels of optimization and better performance, by those who use them in the productive sector, as in the area of intensive farming systems, with low greenhouse gas (GHG) emissions for creating value in production chain, sustainability and competitiveness in the long term agree to the European Union (EU), on the road to a circular economy in Europe [1].

\section{Motivation, objectives and methodology}

Since 2009, the EU acceded to reduce GHG emissions from the energy production, transportation and consumption sectors by 80 to 95 per cent till 2050 in the EU countries, as compared to 1990 levels - an objective to ensure the global temperature does not continue to grow. The contribution of the energy sector is critical to this decarbonize endeavor by 2050. A lot of decisions taken today influence the EU's ability to meet its decarbonization goals [2].
On the other hand, there is a need to implement actions that will fulfill government commitments, in compliance with the program 20-20-20 until 2020. The UE, to meet the European Directives' requirements, should promote the energy efficiency and its rational, avoiding energy waste and stimulate the use of energy renewable sources [3], [4], [5].

The economic viability of agricultural crops produced in protected environments is very dependent on the energy and environmental costs associated with them. The monitoring of greenhouses variables, as well as the definition of solutions tending to minimize production costs are fundamental for the survival and competitiveness of these companies. Constant control of temperature, luminosity, humidity, in thermally stable and sustainable environments throughout the year, is required for correct plant growth and pest control.

The main objective of this research consists in a solution, that reduces the energy consumption of a floriculture greenhouse,

in the analysis as the energy consumptions are carried out and propose, consequently multiple actions that lead to an energy saving and stand out: changing of the primary energy source from fossil to renewable energy (biomass and solar system) and present solutions that increase the energy efficiency of this productive process, for less carbon consuming (as illustrate in the Figure 1).

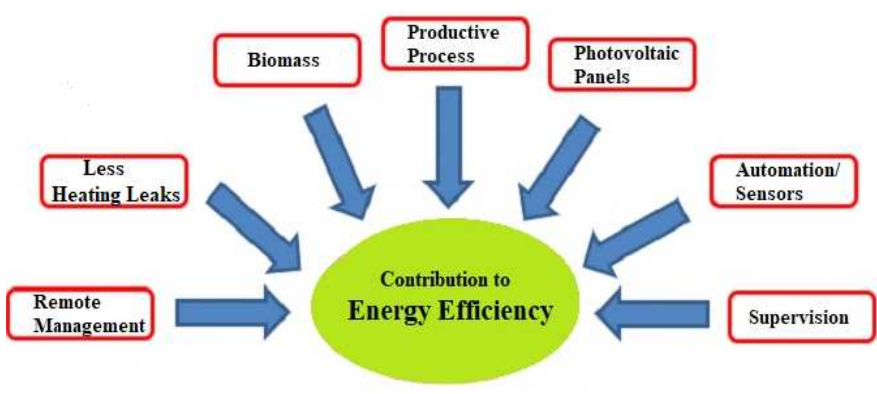

Fig. 1. Areas to improve energy efficiency and susceptible of decarbonization in this typology of agricultural production. 
Initially data information were collected about the energy consumptions (primary energy fuels), architectural structure of the greenhouse to propose areas of intervention, by energy audit according to the national legislation, which is a transposition of a European directive.

This study also took into account the experience of some authors in intensive cultivation of plants (for food or other use), to improve agricultural manager conditions and quality of the plants produced [6], [7], [8].

\section{A. The importance of the production of edible plants in greenhouses}

In the food area, there are trends related to the vegan food movement and the potentialities of edible flowers (like dahlia and rose) as a source of phenolic compounds, with bioactive potential that can be incorporated in human diet [9], [10]. The antioxidant activity of the edible flowers can be very high, when compared to conventional vegetables and fruits used in human diet (from 3.6 for Calendula officinalis to 70.4 for Tagetes erecta) [11]. The diversity of flavors provided by those flowers is very rich and can greatly improve the organoleptic characteristics of the new foods.

There are many challenges in this opportunity, including the production and harvesting methods, storage, packaging, quality control (storage temperature and visual quality) and marketing strategies [12].

The production of edible flowers in a typology called photovoltaic greenhouses can be also a sustainable possibility. Not only the production's methods can be optimized (ex. the microclimate created can reduce pests), as also makes it possible to generate electricity (as was demonstrated in a tomatoes' experimental greenhouse covered with flexible photovoltaic panels) [13].

The search for different sources of nutrients (eg. flowers) to be incorporated in human diet combined with best sustainable production practices, using advanced technologies, can provide huge opportunities to improve, not only the productivity, but also the final product quality.

\section{Analysis of energy data and the structure of the greenhouse}

The methodology followed was based on an energy audit, as mentioned, in the case study chosen requires a number of details of the energy consumptions, as electrical energy and those inherent to the process of heating and cooling of the greenhouse indoor space and respective thermal energy leaks.

The greenhouses selected as case study are located in Cortes, near Leiria city, in Portugal. In the beginning of 2018 the current production area is $5,450 \mathrm{~m}^{2}$, but it will be expanded by the end of this year to $6,816 \mathrm{~m}^{2}$ (Figure
2). Here are produced several flower cultures, especially the carnations and gerberas. The air conditioning in the winter is currently ensured by a hot air generator using fossil fuel (diesel). The heating period considered is 140 days.

At the beginning of the Spring, the monitoring of electric energy consumptions happend for 3 weeks (from March 26 to April 15) and the results are presented in Figure 3, which show a maximum electrical consumption of $8401,5 \mathrm{~W}$ (Watt) and an average consumption of 672,8 $\mathrm{W}$. The pace of sample registration was every 5 minutes. During the night there was no consumption. The daily activities and consumption begin at 7 o'clock.

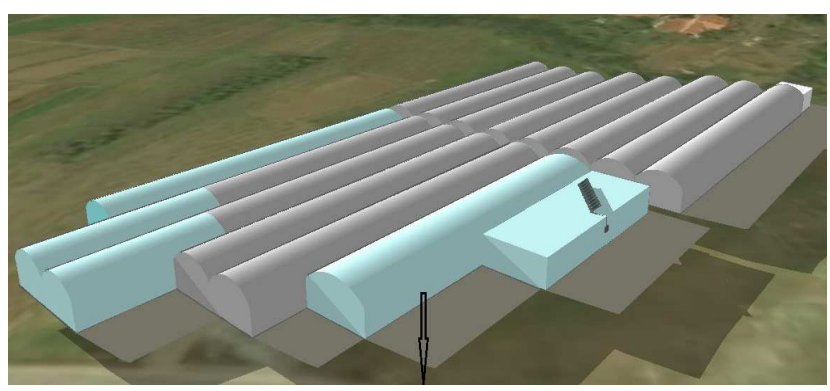

Fig.2. Perspective of greenhouse expansion (light green color) and the nutrient preparation zone

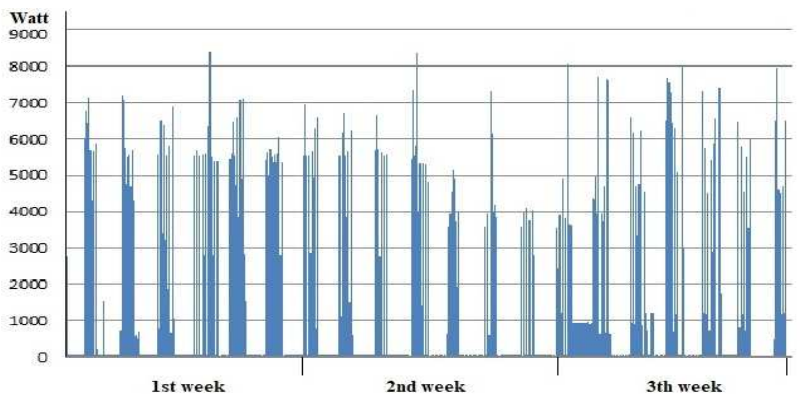

Fig. 3. Electricity consumption sampling in Spring period

A day of greater consumption is presented in Figure 4. Exceptionally on this day the consumption lasted until around 10:30p.m. The electrical energy consumption during the day consisted of a maximum of 8401,5Watt with an average of 1023,995 Watt.

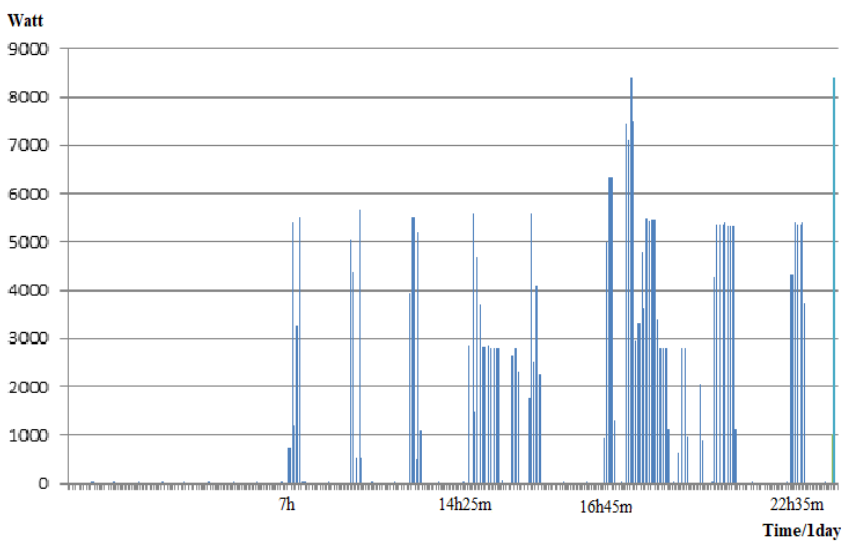

Fig. 4. Day with a great electrical consumption 
During fieldwork, a thermographic analysis was performed in the greenhouses. This analysis was purposely carried out at night because of the more pronounced thermal amplitude indoor/outdoor. From the result of this analysis, it was possible to identify the points with marked heat loss (blue parts), as shown in Figures $5 \mathrm{a}$ ), b). The correction of this problem would result in the acquisition and placement of a thermal blanket, which is a plastic cover that runs and collects along the space, according to the indoor temperature of the greenhouse.
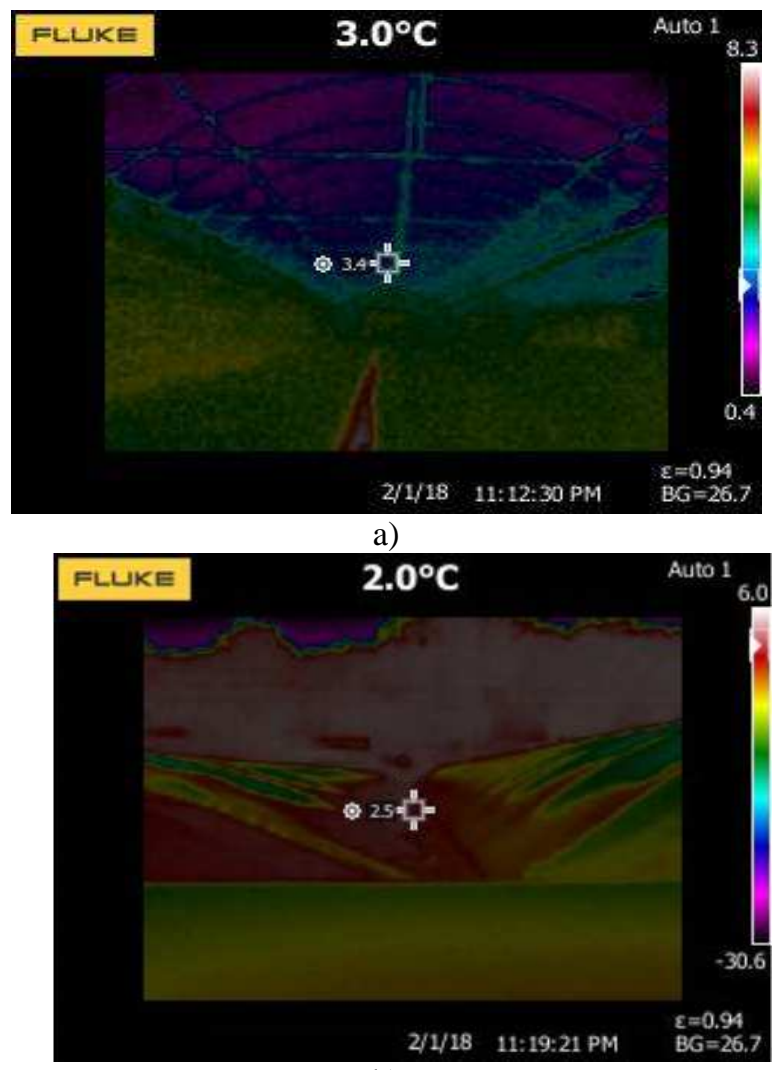

b)

Fig. 5. Energy thermal analysis: a) Indoor leaks in Winter season, represented by the blue color; b) Rooftop outdoor temperature

There are several types of greenhouse structures and the best known are the circular, tunnel, two-way and sawtooth types. The typology of this study case is the tunnel type. Greenhouses are an investment based on technology and due to this, for each type of greenhouse is associated a technological typology, as well as the expected health and productivity of the crop to be produced [14].

\section{Stages of the developed system and results}

It is important to highlight the project of a biomass boiler, a photovoltaic power plant, a management and supervision system, which leads to a set of actions of energy efficiency and several simulations were carried out, with the support of a mix of softwares associated to each development stage of this energy model, such as: Skecthup; AutoCad; WebVisit; PcWork; Sunny Design and PVsyst [15], [16];
As an alternative to the existing heating system and diesel, it is proposed a biomass heating system where it will be possible not only to reduce $\mathrm{CO}_{2}$ emissions, but also to obtain primary renewable energy at a lower cost. In this context, a boiler, an inertia tank and a storage tank for the biomass (woods chips) were designed. In the same way, a photovoltaic power plant for electricity production was projected and the payback of both investments was studied, as also the advantages in terms of reduced $\mathrm{CO}_{2}$ emissions.

In order to obtain the energy balance, all the losses existing in the corresponding, process are presented in equation (1).

$$
\text { QClimate = Qcc + QRAD + Qsolo + QREN }
$$

Using the formulas in Tables 1 and 2, all existing losses were calculated considering the factors in Table 1.

Table 1 - Losses equations

\begin{tabular}{|l|l|}
\hline $\begin{array}{l}\mathrm{Q}_{\mathrm{CC}}-\text { Conduction } \\
\text { loss/Convection }\end{array}$ & $\mathrm{Q}_{\mathrm{CC}}=\mathrm{K} * \mathrm{Sc} *(\mathrm{Ti}-\mathrm{Te})$ \\
\hline $\begin{array}{l}\mathrm{Q}_{\mathrm{RAD}}-\text { Radiation losses } \\
\mathrm{Q}_{\mathrm{RAD}}=5,67 * 10^{-8} * \mathrm{Sr} * \mathrm{P} * \\
\left(\mathrm{Ti}^{4}-\mathrm{Te}^{4}\right)\end{array}$ \\
\hline $\mathrm{Q}_{\mathrm{REN}}-$ Indoor air loss & $\begin{array}{l}\mathrm{Q}_{\mathrm{REN}}=\mathrm{N} * \mathrm{~V} * 0,307 *(\mathrm{Ti}- \\
\mathrm{Te})\end{array}$ \\
\hline $\mathrm{Q}_{\mathrm{SOLO}}-$ Losses through soil & $\mathrm{Q}_{\mathrm{SOLO}}=\mathrm{Ks} * \mathrm{Sc} *(\mathrm{Ti}-\mathrm{Te})$ \\
\hline
\end{tabular}

The input parameters listed in Table 2 for the heating power simulations, taking into account the existing greenhouse areas (and future expansion), the manager information about the needs required for each species of flowers produced.

Table 2 - Data for the calculation of heating power

\begin{tabular}{|c|c|}
\hline Sr - Area of planting of greenhouses & $32.853 \mathrm{~m}^{3}$ \\
\hline Sc - Coverage area & $13^{\circ} \mathrm{C}$ \\
\hline V - Total greenhouses volume & $3^{\circ} \mathrm{C}$ \\
\hline Average indoor temperature & $18^{\circ} \mathrm{C}$ \\
\hline Ti - Minimum outdoor temperature & $3,5 \mathrm{~m} / \mathrm{s}$ \\
\hline Te - Average outdoor temperature & 5 months \\
\hline Average wind speed & $\begin{array}{c}8 \mathrm{~W} / \mathrm{m}^{2} \\
{ }^{\circ} \mathrm{C}\end{array}$ \\
\hline Period of heating needs & $\mathrm{N}=1$ \\
\hline $\begin{array}{l}\text { K - (global coefficient of heat transfer) used } \\
\text { plastic }(200 \mu \mathrm{mm})\end{array}$ & $\begin{array}{c}0.307 \\
\mathrm{kcal} /{ }^{\circ} \mathrm{C} . \mathrm{m}^{3}\end{array}$ \\
\hline $\mathbf{N}$ - (number of air renovations air/hour), & $\begin{array}{l}5,67 * 10-8 \\
\mathrm{~W} / \mathrm{m}^{2} \mathrm{~K}^{4}\end{array}$ \\
\hline $\begin{array}{l}\text { Product constant, specific air weight and } \\
\text { specific heat }\end{array}$ & 0.8 \\
\hline Constant of Stefan Boltzmann & $\begin{array}{c}1.1 \\
\mathrm{~W} / \mathrm{m}^{2}{ }^{\circ} \mathrm{C}\end{array}$ \\
\hline $\mathbf{P}$ - (permeability coverage coefficient) & 0.8 \\
\hline $\begin{array}{l}\text { Ks - (coefficient of heat exchange through the } \\
\text { soil) }\end{array}$ & $\begin{array}{c}1.1 \\
\mathrm{~W} / \mathrm{m}^{2}{ }^{\circ} \mathrm{C} \\
\end{array}$ \\
\hline
\end{tabular}

As result of the total losses, the boiler power was determined assuming the efficiency of the boiler and the 
fact that the production never exceeds $90 \%$ of the requirements simultaneously. With this, we obtain the value of $1,200 \mathrm{~kW}$ thermal for the nominal power of the boiler, resulting in option for the boiler shown in equation (2), being that, †boiler is the efficiency of boiler.

$$
\text { Pboiler }=\text { Qclimate } * \eta \text { boiler } * 0,9
$$

In Table 3 there are presented features among some of the possible fuels to be used. It should be noted that these values are approximate, considering that they vary due to external factors [17]. The wood chips presents at a very good price.

Table 3 - Main biomass energy fuel for this boiler

\begin{tabular}{c|cccc}
\hline Designation & $\begin{array}{c}\text { Olive } \\
\text { pomace }\end{array}$ & $\begin{array}{c}\text { Wood } \\
\text { chips }\end{array}$ & Pellets & $\begin{array}{c}\text { Almond } \\
\text { shell }\end{array}$ \\
$\begin{array}{c}\text { Humidity }(\%) \\
\text { Lower }\end{array}$ & 9 & 23 & 8 & 13 \\
$\begin{array}{c}\text { Calorific Value } \\
(\mathrm{MJ} / \mathrm{kg})\end{array}$ & 13 & 12 & 19 & 16 \\
\begin{tabular}{c} 
Price $(€ /$ tonne $)$ \\
\hline
\end{tabular} & 60 & 55 & 125 & 75 \\
\hline
\end{tabular}

This equipment that are part of the energy efficiency improvement proposal presented in Figure 1 can be controlled and managed remotely by the monitoring and supervision system presented below (Figures 6 and 7). The interface consists on a friendly group of web pages that allow the data system and to the biomass boiler variables. They are designed to provide adequate control over the use of the boiler and the storage tank of the biomass (wood chips).

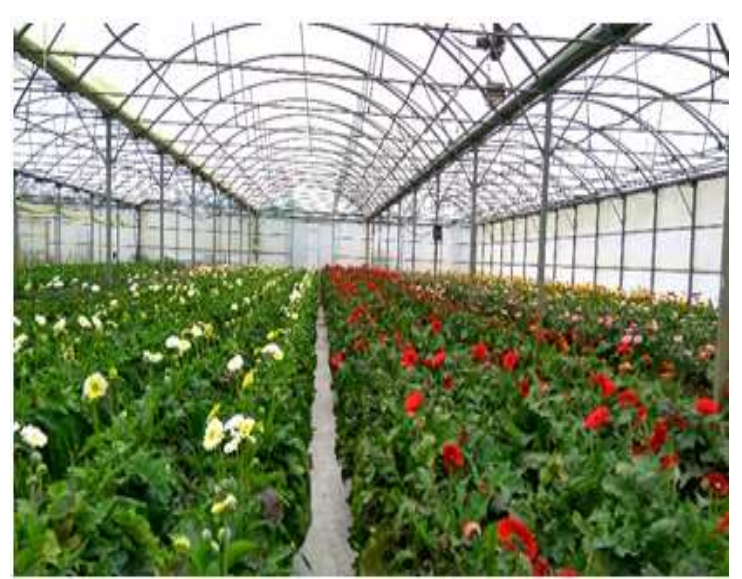

Fig. 6. General production view of gerberas

On previous images it is possible to check the status of some variables related to the operation of this boiler, like if is on or off, the quantity of wood chips that are in the biomass tank and the condition of the valves of the different heating circuits, being thus possible to know the hours of greater consumption system and keys for future expansion (Figure 8).

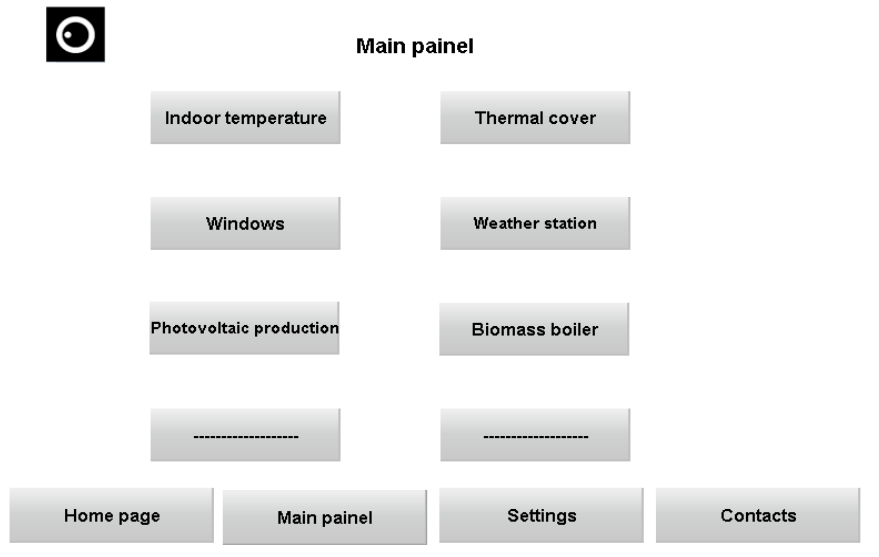

Fig. 7. Main menu of the data management system developed

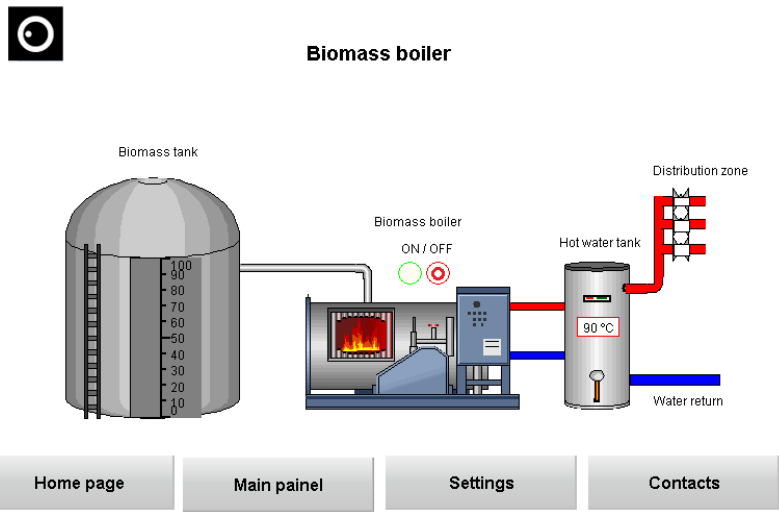

Fig. 8. Visualization of variables resulting from the biomass boiler operation.

The economic and financial analysis was done and the estimated investment is around 166,400 $€$ excluding VAT tax, so for the economic and financial analysis the current values of fuels and equipment were considered. The study of the system implies an analysis over 20 years, considering the following factors:

- Increase of electric energy $3.2 \%$ per year (data from ERSE) [18];

- Capital increase rate at $2 \%$;

- Annual depreciation of production at $0.70 \%$ (value indicated by the manufacturer);

- Annual maintenance of the system as a whole of $0.70 \%$ of the amount invested.

By calculating the predicted investment and the expected benefits of the biomass system, the following economic and financial values were obtained: NPV (net present value), Payback and Break Even (balance point where there is no loss or profit), Figure 9. 


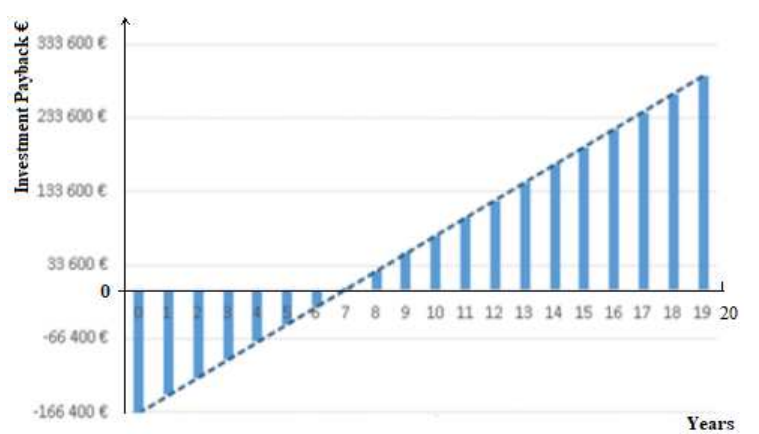

Fig. 9. Boiler investment payback evolution and break even (near 7 years)

Another efficiency action of this case study was the design of the photovoltaic power plant, which had as reference the electrical consumptions analyzed over the last years and collected in the sample period of Figures 3 and 4 . Since they are relatively low, the photovoltaic power plant will scale and propose a system for selfconsumption, according to the governmental legislation, but connected on to the electrical grid and consequent reduction of electricity costs.

The software selected for the execution of the sizing was the PVsyst. For the simulation it is important to take into consideration, firstly the location of the photovoltaic installation. This facility will be in in the geographical coordinate $39^{\circ} 42^{\prime} 36.7$ "N of latitude and $8^{\circ} 47^{\prime} 16.2^{\prime \prime} \mathrm{W}$ of longitude and at an altitude of 67 meters above sea level. These data will be inserted in the software to obtain the values of irradiation, temperature and wind speed [19].

When carrying out a sizing of photovoltaic systems, one of the important aspects to be considered is the level of solar radiation available for the installation site, the number of hours in which it is possible to capture solar energy and if there is currently shading or if there is a possibility to exist.

The design of the electrical cables and protections was done through the software Sunny Web Design. This allowed us to determine the type and section of the cable considering the distance to be covered, the current and voltage that will go through it and the voltage drop and as well as the percentage of the voltage drop that be less than $1 \%$. The electrical cables will be divided into two sections: one that will go from the panels to the inverter and another that will go from the inverter to the equipment that feeds the electrical grid. The first section will consist of a copper cable with a section of $1.5 \mathrm{~mm}^{2}$. It was estimated that this will be about 12 meters and that there will be a percentage of the voltage drop of $0.5 \%$.

In order to monitor the data management system, an automated control system was implemented. The monitoring system consists on a collection and processing of data through the ILC 150 automaton, which is available on a web page as well as in an excel file, exported from the database, which integrates the PC Worx and WebVisit programs, as well as, the MySQLWorkBench software that is an open source relational database management system that is based on the SQL (structure query language) [20]. It was used for removing, adding and modifying information in the database. The Figures 10 and 11 are originated from a several sensor inputs.

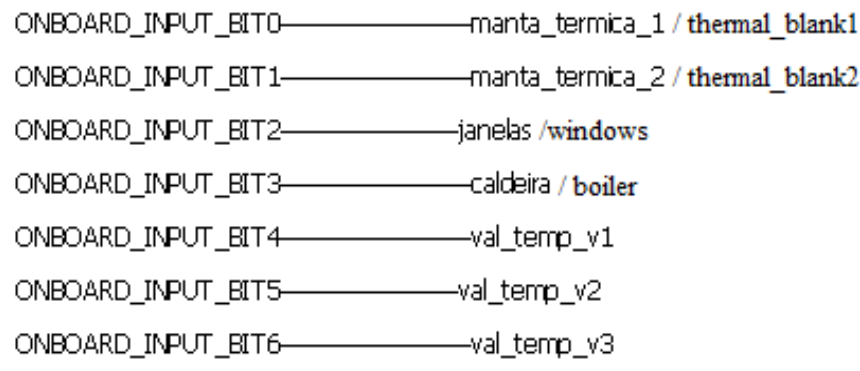

Fig. 10. Digital inputs in PcWork

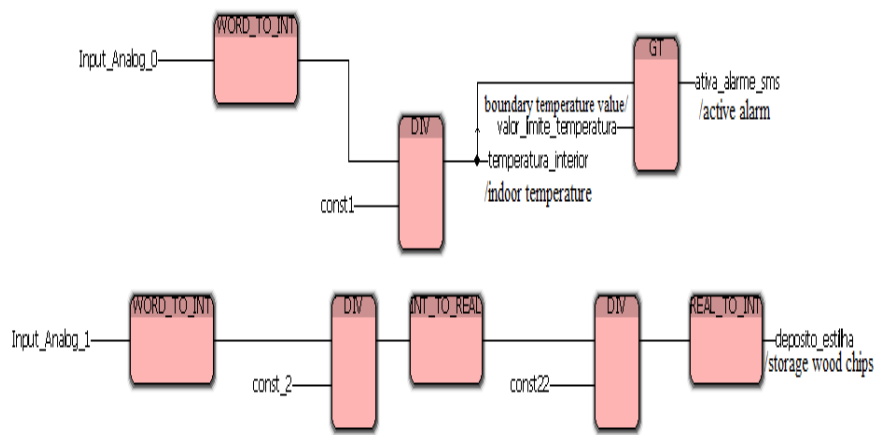

Fig. 11. Analog inputs in PcWork

The GSM (global system for mobile communication) module of the chosen automated equipment is used to send a warning the company manager's telephone in order to communicate that the indoor temperature in the greenhouses has exceeded the predicted parameters, so that it must take a corrective action, Figure 12. For instance, it could either open the windows to cool down or to increase the heat to be distributed inside the growing area [21].

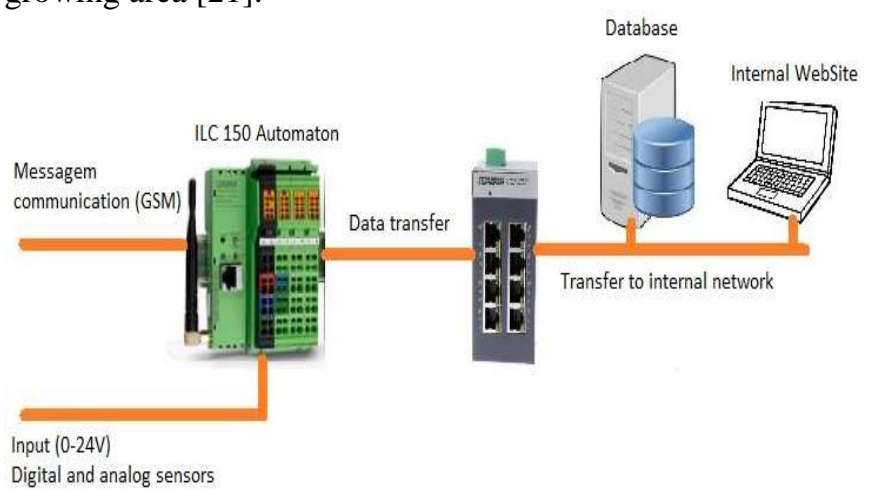

Fig. 12. Data management and supervision system diagram

Finally, it is possible to highlight the graphic interface designed to interact in a simple and effective way with the several functionalities of the system presented here. This interface has been programmed to work based on a menu of tabs and aims to facilitate navigation between 
the different variables and information available in the database for better management and control of the flowers production.

In the greenhouses the automation systems to be implemented in the areas of irrigation, fertilization and indoor climate control can directly influence the quality of production and increase owner's profit.

\section{Conclusion}

This research aimed to increase energy and environmental efficiency, as well as to visualize in real time, the main parameters that imply the operation of a greenhouse complex. The reduction of energy consumption and a system of supervision and data management were the two areas that had the greatest focus in the conception of this project. In order to maximize the energy efficiency, an audit of the greenhouse case study was carried out to obtain the consumptions made during the sampling period, which were used to calculate the annual consumption, considering already a future expansion of the installations and later development of the areas presented in the new energy model. This will allow to achieve the objective of reducing production costs and to increase the efficiency and management, with the consequent lower emissions.

Tests were carried out in this case study with results that support the desired improvements and that will lead in the short term, to the promotion of this model within several types of greenhouses, whether they are used for intensive production of decorative plants or for human consumption in large scale, supported by the digitalization and interconnection among systems and with the IoT concept.

\section{Acknowledgement}

This work has been partially supported by the Portuguese Foundation for Science and Technology under the project grant UID/Multi/00308/2019.

\section{References}

[1] European Commission, Implementation of the Circular Economy Action Plan, http://ec.europa.eu/environment/circulareconomy/index_en.htm, access on 2 February 2018.

[2] Decarbonization in the European Union: Internal Policies and External Strategies (Energy, Climate and the Environment), Claire Dupont , Sebastian Oberthür, (Editor), 2015, ISBN-10:1137406828.

[3] ENE - Estratégia Nacional para a Energia 2020/ Portuguese National Strategy for Energy 2020, Council of Ministers Resolution 29/2010, 15th of April.

[4] European Commission, Rational Use of Energy in Europe, https://ec.europa.eu/energy/en/topics/energy-efficiency/energyefficiency-directive; access on 22 January 2018.

[5] European Parliament, Promotion of the use of Energy from Renewable Sources, https://eur-lex.europa.eu/eli/dir/2009/28/oj; access on 10 December 2017.

[6] F. Oliveira; S. Leitão; A. Nabais; R. Ascenso; J. Galvão, Greenhouse with Sustainable Energy for IoT, In Technological Innovation for Cyber-Physical Systems - DoCEIS 2016 Conference Book, pages 416 - 424. ISBN: 978-3-319-31164-7; Springer International Publishing, 2016; doi: 10.1007/978-3319-31165-4_39.
[7] A. Nabais, R.M.T. Ascenso, J.R. Galvão, Efficiency in Greenhouse for intelligent Management Energy, International Conference on Innovative Technologies In-Tech, 2016, ISSN 1849-0662, Prague, (2016), http://www.in-tech.

[8] J.R. Galvão; M.A. Almeida; R.M.T. Ascenso; V.S. Ribeiro, Green Roofs for Energy Efficiency and Smart Food Production to Sustainability, Environment, Green Technology and Engineering International Conference (EGTEIC), Caceres/Spain, (2018), 18-20 June; ISBN 9788417238865.

[9] T. Leenaert, How to Réate a Vegan World: a Pragmatic Approach, Editor Lantern Books, New York (2017); ISBN 9781590565711 (ebook) www.lanternbooks.com.

[10] Pires, T.C.S.P., et al., Edible Flowers as Sources of Phenolic Compounds with Bioactive Potential, Food Research International, (2018). 105: p. 580-588.

[11] Benvenuti, S., E. Bortolotti, and R. Maggini, Antioxidant Power, Anthocyanin Content and Organoleptic Performance of Edible Flowers, Scientia Horticulturae, (2016). 199: p. 170177.

[12] Kelley, K.M., et al., Effect of Storage Temperature on the Quality of Edible Flowers, Postharvest Biology and Technology (2003). 27(3): p. 341-344

[13] Ezzaeri, K., et al., The effect of photovoltaic panels on the microclimate and on the tomato production under photovoltaic canarian greenhouses, Solar Energy (2018). 173: p. 1126-1134, https://doi.org/10.1016/j.solener.2018.08.043.

[14] NSW Government, Department of Primary Industries, Types of Greenhouses, Online:

https://www.dpi.nsw.gov.au/agriculture/horticulture/greenhouse /structures-and-technology/types; access on 10 March 2018.

[15] Sunny Design WEB, New Project, Sunny Design,Online: https://www.sunnydesignweb.com/sdweb/\#/Home; acess 15 December 2017.

[16] PVsyst program, Data Irradiation, Wind and Temperature in Case Study, Online: https://www.pvsyst.com/, access on 9 December 2017.

[17] Iberia Biomass, Biomass Products Catalog, http://iberiabioenergy.com/markets-trade/biomass/; acess 10 April 2018.

[18] ERSE - Entidade Reguladora Serviços Energéticos/Energy Services Regulatory Authority, Online:

http://www.erse.pt/eng/Paginas/ERSE.aspx, access 20 April 2018

[19] Joint Research Centre, Institute for Energy and Transport EU, Photovoltaic Geographical Information System; Monthly Radiation, Available:

http://re.jrc.ec.europa.eu/pvgis/apps4/pvest.php\#, access on 10 January 2018.

[20] Phoenix Contact, Industrial PCs, Programmable Controllers and Software, Online:

https://www.phoenixcontact.com/online/portal/us?1dmy\&urile $=$ wcm $\% 3$ apath $\% 3 \mathrm{a} / \mathrm{usen} / \mathrm{web} / \mathrm{main} /$ resources $/$ subcategory_page s/Technical_notes_and_application_notes/3f64c13a-3093-40a9a258-08e159bb250d\#sectione328e475-b57c-458d-9239d37d1f67c245; access on 25 March 2018.

[21] Phoenix Contact, Communication Module, Online: https://www.phoenixcontact.com/online/portal/us?uri=pxc-ocitemdetail:pid $=2708902 \&$ library $=$ usen $\&$ tab $=1$; access on 3 May 2018. 